\title{
Perception of Company Leaders on opportunities and Challenges of Integrated Reporting in India
}

\author{
Nandita Mishra \\ Amity University Uttar Pradesh, Noida
}

\begin{abstract}
The main purpose of this paper is to analyses the perception of the Company's leaders on challenges and opportunities with respect to Integrated Reporting $\langle\mathrm{R}\rangle$ in India. This paper studies the current status of $<\mid R>$ in India, especially after the SEBI's mandate in Feb 2017, where it has encouraged Top 500 listed companies to adopt $<\mathrm{IR}>$ framework for corporate reporting. SEBI had given one year time to the companies to adopt $\langle\mathrm{R}\rangle$ and therefore it would be interesting to know about the current status of $<\mathrm{IR}>$ adoption and the perception of company's leaders towards $<\mathrm{IR}>$. In today's economy companies are facing global competition, technological innovation and increased regulation imposed on them in response of Governance and Financial Crisis. Over the past two decades standalone social and environmental disclosures have increased adding more and more pressure on companies to give non-financial disclosure. $<I R>$ is a logical reply in reporting financial and non-financial disclosures. In this paper top 500 companies from ET 500 list published by Economic times for 2018-2019 has been taken. Companies trading on less than $75 \%$ of the total trade days on BSE during the total trade days has been excluded. Banks and financial institutions (total 69) has been excluded for the study. Out of 431 companies, the status of Integrated Reporting has been checked as how many companies follow $\langle\mathbb{R}>$ and a questionnaire based survey has been conducted on those companies who follow $\langle\mathbb{R}\rangle$. Questions relating to advantages and disadvantages of $\langle\mid R\rangle$, opportunities and challenges of \langle|$R>$ has been framed on the Likert scale of 5 and a descriptive analysis was performed to study the perception of the leader of company who deal with finances of the company. The result shows that the leaders have positive opinion about $\langle\mid R\rangle$, they believe in the advantages and opportunities that $\langle\mathrm{IR}\rangle$ will provide. But respondents also believe that there is a need for training related to the Framework of six capitals of $\langle\mid R\rangle$ and for audit assurance of $\langle\mathrm{IR}\rangle$
\end{abstract}

Keywords. Non-Financial Disclosures; BRR Reports; CSR Report; Audit Assurance; Challenges; Opportunities. 